\title{
Back Surface Recombination Velocity Modeling in White Biased Silicon Solar Cell under Steady State
}

\author{
Ousmane Diasse1, Amadou Diao', Mamadou Wade', Marcel Sitor Diouf', \\ Ibrahima Diatta1, Richard Mane', Youssou Traore', Gregoire Sissoko ${ }^{1}$ \\ ${ }^{1}$ Laboratory of Semiconductors and Solar Energy, Physics Department, Faculty of Science and Technology, University Cheikh \\ Anta Diop, Dakar, Senegal \\ ${ }^{2}$ Laboratory of Sciences and Techniques of Water and Environment, Polytechnic School of Thiès, Thiès, Senegal \\ Email: gsissoko@yahoo.com
}

How to cite this paper: Diasse, O., Diao, A., Wade, M., Diouf, M.S., Diatta, I., Mane, R., Traore, Y. and Sissoko, G. (2018) Back Surface Recombination Velocity Modeling in White Biased Silicon Solar Cell under Steady State. Journal of Modern Physics, 9 , 189-201.

https://doi.org/10.4236/jmp.2018.92012

Received: December 15, 2017

Accepted: January 19, 2018

Published: January 22, 2018

Copyright $\odot 2018$ by authors and Scientific Research Publishing Inc. This work is licensed under the Creative Commons Attribution International License (CC BY 4.0).

http://creativecommons.org/licenses/by/4.0/

\begin{abstract}
In this paper, we extend the concept of back surface recombination through a study of a silicon mono facial solar cell in static regime and under polychromatic illumination. Back surface recombination velocities noted Sbe, Sbj and $S b r$ are determined for which respectively we derived, the power, the fill factor and the conversion efficiency, that become constant whatever the thickness of the solar cell. We have then obtained the expression of the minority carrier's density in the base from the continuity equation. We then have determined the photocurrent density, the photo voltage, the power, the fill factor and finally the conversion efficiency.
\end{abstract}

\section{Keywords}

Silicon Solar Cell, Surface Recombination Velocity, Thickness

\section{Introduction}

Today one of the main objectives in the domain of the photovoltaic energy is to improve the solar cell efficiency and to reduce the manufacturing cost. Until now, the conversion efficiency in photovoltaic solar is in the order of $20 \%$ in the laboratories but only in the order of $17 \%$ to the commercial level. This objective has to optimize the solar cell thickness $(H)$ and the recombination parameters in the bulk and surfaces.

These recombination [1] parameters can be studied in static regime [2] [3] [4] or in dynamic regimes i.e. transient [5] [6] or frequency [7] [8] [9] [10]. Otherwise, 
the photogenerated carriers are submitted to the recombination in the bulk and on the surfaces. The processes of recombination limit then the solar cell efficiency. We propose in this paper, to study the effect of both the solar cell thickness and the back surface recombination velocity, through the carrier density, the photocurrent density, the photovoltage, the power, the fill factor and the conversion efficiency.

\section{Theory}

\subsection{Presentation of the Solar Cell (Figure 1)}

We consider an $\mathrm{n}^{+} \mathrm{p}-\mathrm{p}^{+}$polycrystalline monofacial silicon solar cell. In this work, we overlook the contribution of the emitter to the photocurrent density compared to the base. When the solar cell is illuminated by the emitter front side.

\subsection{Minority Carrier Density}

Considering generation, recombination and diffusion phenomena of excess minority carriers in the base, the well-known continuity equation is written as:

$$
\frac{\partial^{2} n(x)}{\partial x^{2}}-\frac{n(x)}{L_{n}^{2}}=-\frac{G_{n}(x)}{D_{n}}
$$

With:

$n(x)$ is the excess minority carrier density at the position $x$ in the base;

$D_{n}$ and $L_{n}$ are respectively the diffusion coefficient and the minority carriers diffusion length.

$L_{n}$ and $D_{n}$ are linked by the well-known Einstein expression:

$$
L_{n}=\sqrt{D_{n} \tau_{n}}
$$

$\tau_{n}$ is the excess minority carrier lifetime

$G_{n}$ is the excess minority carriers generation rate.

The $G_{n}$ is in the form of a whole series [11] as it is expressed in following equation

$$
G_{n}(x)=\sum_{\lambda_{0}}^{\lambda_{g}} F_{0 \lambda}\left(1-r_{\lambda}\right) \alpha_{\lambda} \mathrm{e}^{-\alpha_{\lambda} x}
$$

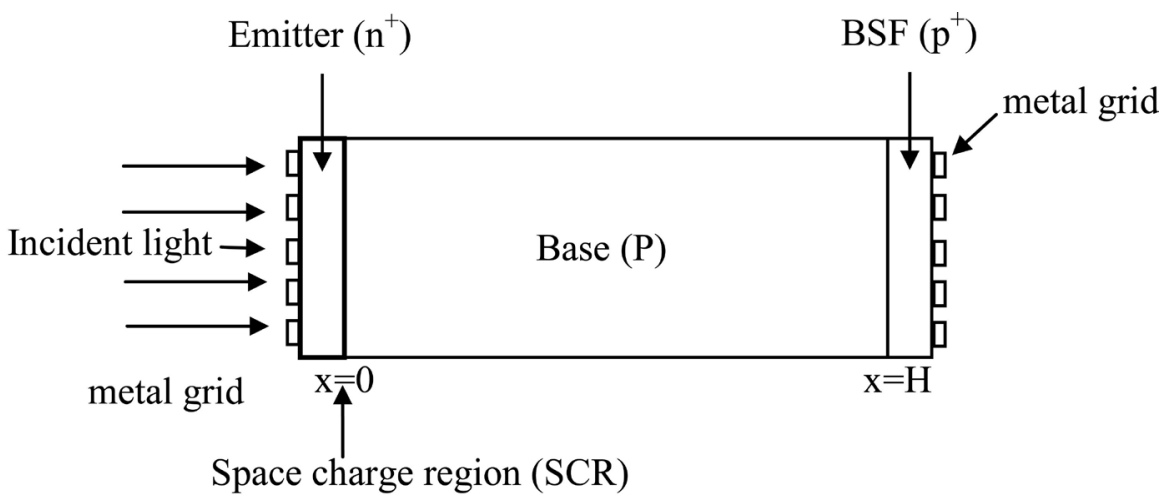

Figure 1. Solar cell illuminated by its front side. 
where $\lambda_{0} \quad(=0.3 \mu \mathrm{m})$ and $\lambda_{g} \quad(=1.2 \mu \mathrm{m})$ are respectively the minimum and the maximum wavelength in the polychromatic source.

$F_{0 \lambda}$ is the incident photon flux; $\alpha_{0 \lambda}$ is the monochromatic absorption coefficient of the material; $r_{0 \lambda}$ is the monochromatic reflection coefficient at the surface of the material;

The solution of the continuity equation with the conventional method can be written as:

$$
n(x)=A \cdot \cosh \left(\frac{x}{L}\right)+B \cdot \sinh \left(\frac{x}{L}\right)+\sum_{\lambda=1}^{\lambda=45} K \cdot \mathrm{e}^{-\alpha x}
$$

$A$ and $B$ are determined by the boundary conditions.

The junction at $x=0$

$$
\left.D_{n} \frac{\partial n(x)}{\partial x}\right|_{x=0}=S f \cdot n(0)
$$

where $S f$ is the minority carrier recombination velocity at the junction [12] [13] [14].

$S f$ is expressed as the sum of two terms: $S f_{0}$ and $S f_{m} \quad S f_{0}$ is related to the shunt resistance. It represent the intrinsic junction recombination velocity.

$S f_{m}$ characterizes the photocurrent collected through the external load $R_{m}$ connected to the solar cell.

At the rear face:

$$
\left.D_{n} \frac{\partial n(x)}{\partial x}\right|_{x=H}=-S b \cdot n(H)
$$

$H$ is the solar cell base thickness and $S b$ is the excess minority carrier recombination velocity at the back surface [15] [16] and yields to low values for sample with back surface field (BSF). $H$ is the solar cell base thickness.

\subsection{Photocurrent Density}

The solar cell photocurrent density is determined from the minority carrier density by the following relationship:

$$
J_{n}(S f, S b)=\left.q \cdot D_{n} \cdot \frac{\partial n(x, S f, S b)}{\partial x}\right|_{x=0}
$$

\subsection{Photovoltage}

The Boltzmann relation gives us the following photovoltage expression as:

$$
V_{p h}(S f, S b)=V_{T} \cdot \ln \left(1+\left.\frac{N_{B}}{n_{i}^{2}} n(x, S f, S b)\right|_{x=0}\right)
$$

With:

$$
V_{T}=\frac{K T}{q}
$$

$n_{i}$ is the intrinsic carrier density, 
$N_{B}$ is the base doping density,

$V_{T}$ is the thermal voltage at a given temperature $T$.

\subsection{Power}

The output electric power is an essential parameter for a solar cell. It indicates the capacity of the solar cell to provide an electricity to the external load. The electrical power produced by the solar cell under polychromatic illumination constant and for a given operating point is determined by:

$$
P=J \cdot V_{p h}
$$

With: $J=J_{p h}-J_{d}$, and

$$
J d=q \cdot n_{1} \cdot S f_{0}\left(\exp \left(\frac{V_{p h}}{V_{T}}\right)-1\right)
$$

$J$ is the photocurrent density in the external load, $J d$ represents the dark current density [14] [17], and $n_{1}=\frac{n_{0}}{N_{b}}, n_{0}$ : carrier density at equilibrium.

\section{Results and Discussions}

\subsection{Photocurrent Density}

We plot on the curves 4 and 5, the profile of the photocurrent density versus junction recombination velocity ( $S f)$ respectively for a given thickness $H$ and for different $S b$ values

On Figure 2, for a given curve, we observed three zones [17]:

i) for the interval $S f \leq 10 \mathrm{~cm} / \mathrm{s}$, the photocurrent is zero. The minority carriers are blocked and stored at the junction. Any carrier crosses the junction: this is the open circuit condition.

ii) in the interval $10 \mathrm{~cm} / \mathrm{s} \leq S f \leq 4 \times 10^{4} \mathrm{~cm} / \mathrm{s}, j$ increases quickly.

iii) in the interval $S f \geq 4 \times 10^{4} \mathrm{~cm} / \mathrm{s}, j$ becomes constant and retains its maximum value corresponding to the short-circuit photocurrent. All the photogenerated carrier crosses the junction: this is the short circuit. The effect of the back surface recombination velocity on the short-circuit photocurrent density is reflected by an increase of the photocurrent density when $S b$ decreases (BSF effect).

On Figure 3(a) and Figure 3(b), it is observed that for slight $S b$ values, the effect of the thickness on the photocurrent is very low. But the photocurrent decreases slightly with the increase of the solar cell thickness (Figure 3(b)). On the contrary for large $S b$ values, the effect of the thickness on the photocurrent density is only visible for large $S f$ values $\left(S f \geq 4 \times 10^{4} \mathrm{~cm} \cdot \mathrm{s}^{-1}\right.$ ).

In this interval, the short-circuit photocurrent density increases with the thickness (Figure 3(b))

For $H \geq 0.02 \mathrm{~cm}$, the photocurrent density becomes nearly constant.

Therefore for thin photovoltaic solar cell (low thickness), the short-circuit 


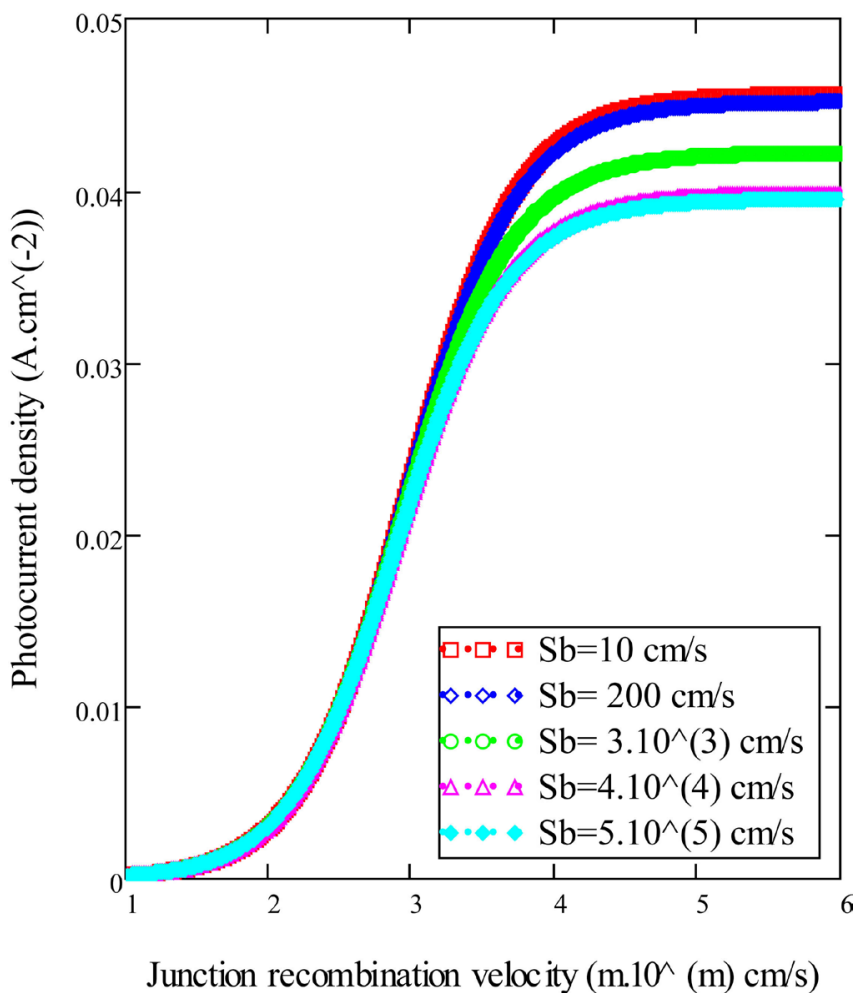

Figure 2. Photocurrent density versus junction recombination velocity for different $S b$ values: $L=0.01 \mathrm{~cm} ; H=0.015 \mathrm{~cm} ; D=26 \mathrm{~cm}^{2} / \mathrm{s}$.

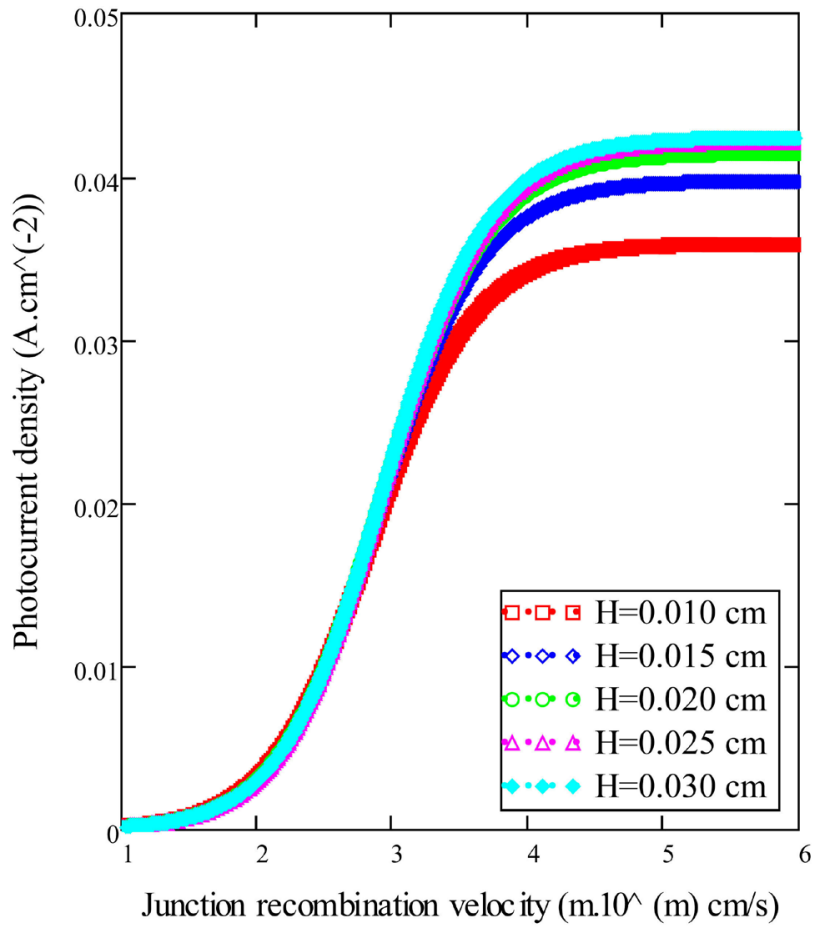

(a)

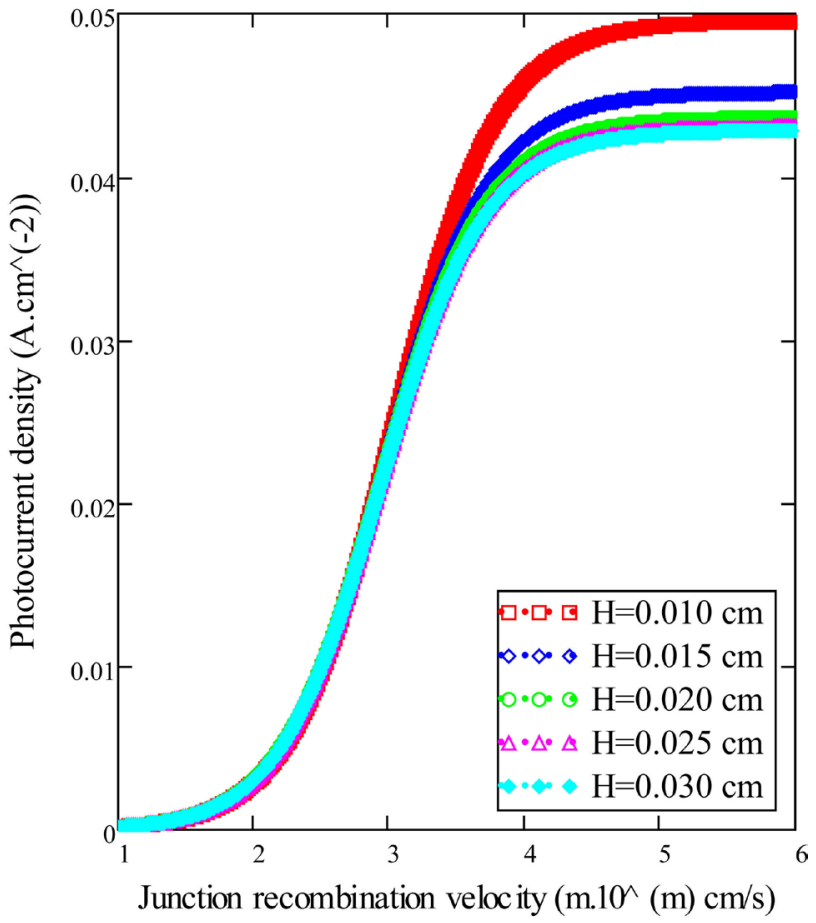

(b)

Figure 3. (a) Photocurrent density versus junction recombination velocity for different $H$ values and for High $S b$ : $S b=4 \times 10^{4} \mathrm{~cm} \cdot \mathrm{s}^{-1} ; L=0.01 \mathrm{~cm} ; D=26 \mathrm{~cm}^{2} / \mathrm{s} ;$ (b) Photocurrent density versus junction recombination velocity for different $H$ values and for slight $S b$ value. $S b=2 \times 10^{2} \mathrm{~cm} \cdot \mathrm{s}^{-1} ; L=0.01 \mathrm{~cm} ; D=26 \mathrm{~cm}^{2} / \mathrm{s}$. 
photocurrent density is higher for the low values of the back surface recombination velocity whereas when the recombination velocity is high, it is more important for thick solar cells.

\subsection{Photo Voltage}

We have plotted on Figure 4 and Figure 5 respectively the effect of $S b$ and thickness on the photo voltage versus junction recombination velocity ( $S f$ ).

On Figure 4, for each curve we observe two zones [17]:

i) in the interval $S f \leq 2 \times 10^{2} \mathrm{~cm} \cdot \mathrm{s}^{-1}$, the photovoltage is constant and corresponds to the open circuit photovoltage $V O C$. Here the carriers photo generated are blocked and cannot cross the junction, their accumulations explain the maximum photovoltage value.

ii) in the interval $S f \geq 2 \times 10^{2} \mathrm{~cm} \cdot \mathrm{s}^{-1}$, the photovoltage decreases rapidly up to cancel itself. This is because all excess minority carriers photo generated gradually cross the junction until there are charges no more: this is the short circuit.

The curves show that for low $S b$ values (Figure 5(a)), VOC decreases with the increase of the solar cell thickness whereas high $S b$, Voc increases with the thickness (Figure 5(b)).

The open-circuit photo voltage is all the more slight that the solar cell is thin for the low back surface recombination velocity. Whereas for the thick solar cells the open-circuit photo voltage is low for high back surface recombination velocity values.

\subsection{Power}

Recognizing the expression of the power, we represent respectively on Figure 6

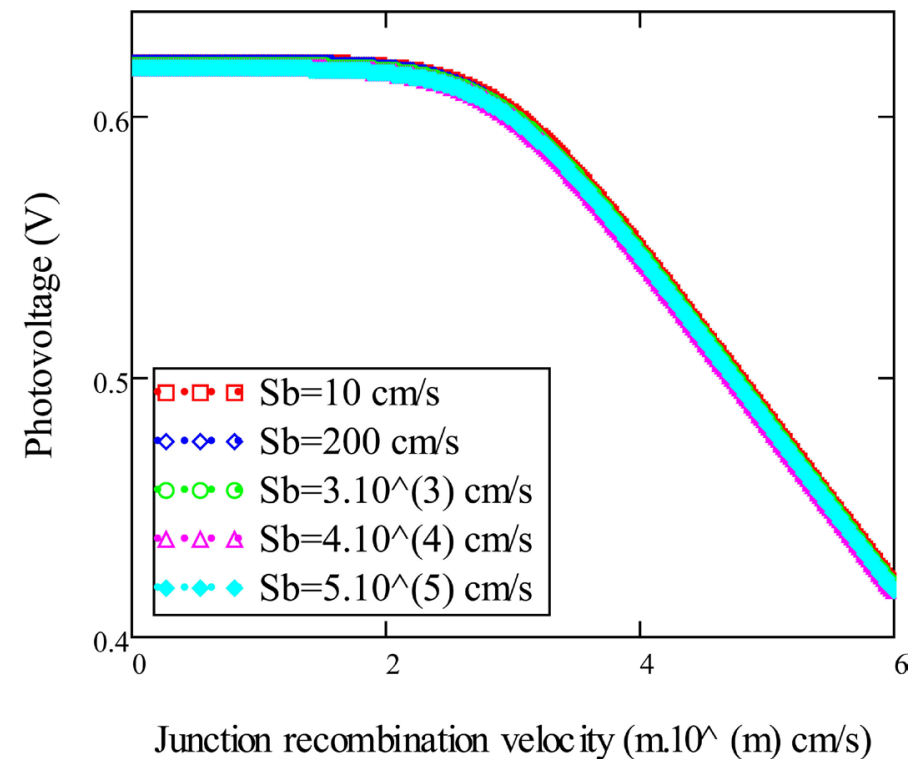

Figure 4. Photovoltage versus junction recombination velocity for different $S b$ values: $L=0.01 \mathrm{~cm} ; H=0.02 \mathrm{~cm} ; D=26 \mathrm{~cm}^{2} / \mathrm{s}$. 


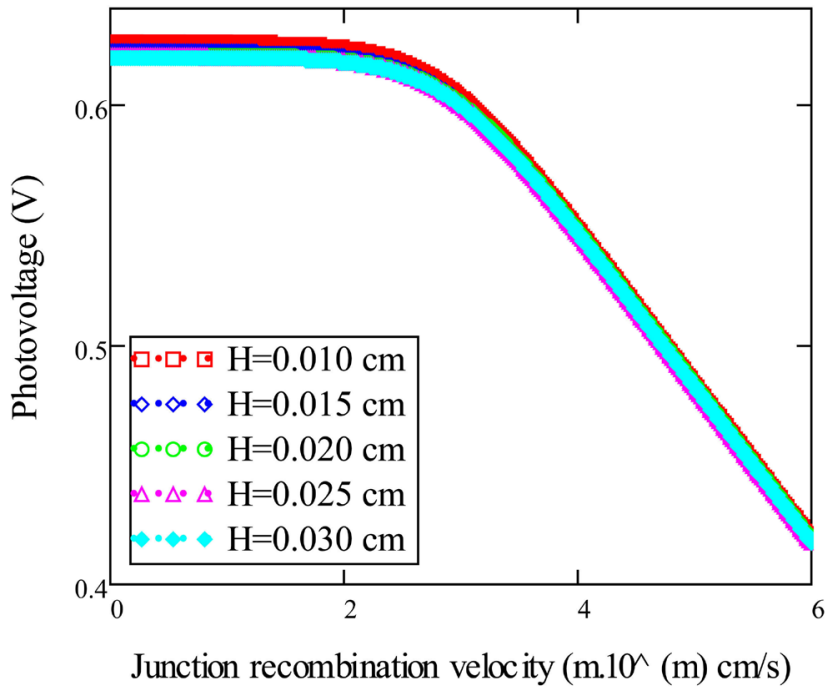

(a)

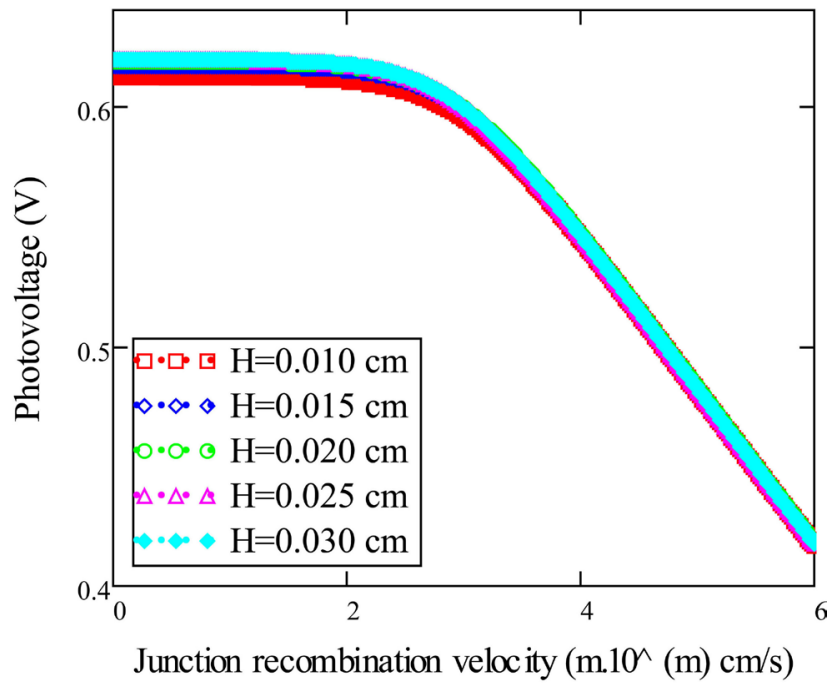

(b)

Figure 5. (a) Photo voltage versus junction recombination velocity for different $\mathrm{H}$ values and for low $S b \quad$ values: $S b_{1}=200 \mathrm{~cm} / \mathrm{s}$; $L=0.01 \mathrm{~cm} ; D=26 \mathrm{~cm}^{2} / \mathrm{s}$. (b). Photo voltage versus junction recombination velocity for different $H$ values and for high $S b$ values $S b_{2}=4 \times 10^{4} \mathrm{~cm} / \mathrm{s} ; L=0.01 \mathrm{~cm} ; D=26 \mathrm{~cm}^{2} / \mathrm{s}$.

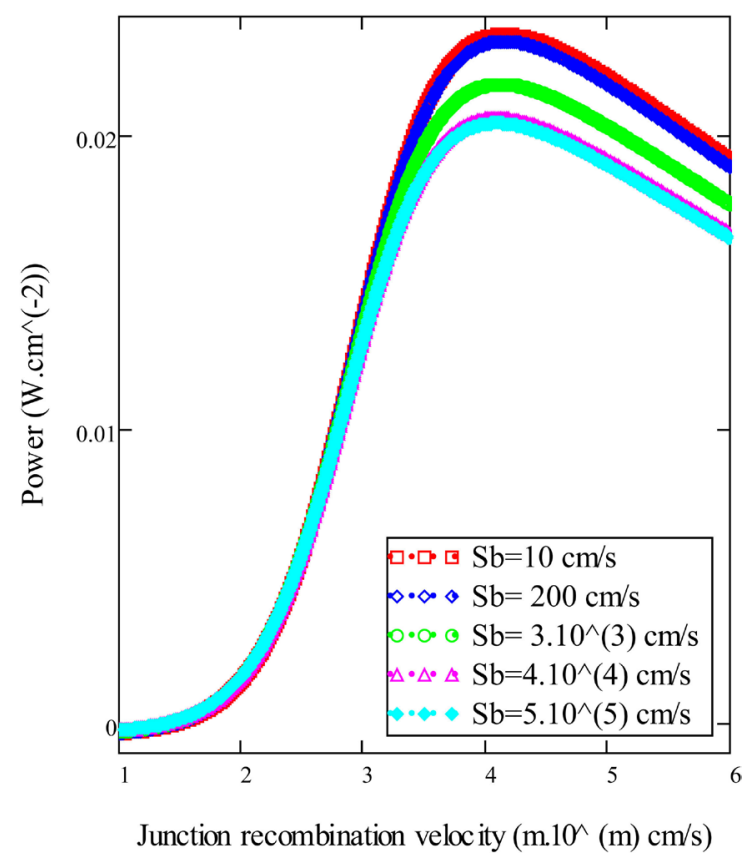

Figure 6. Power versus junction recombination velocity for different $S b$ values: $L=0.01 \mathrm{~cm} ; H=0.015 \mathrm{~cm} ; D=26 \mathrm{~cm}^{2} / \mathrm{s}$.

and Figure 7 the effect of $S b$ and the thickness on the power versus junction recombination velocity $S f$.

On Figure 8, the effect of the thickness $\mathrm{H}$ on the power versus back surface recombination velocity ( $S b$ ) is represented and finally we are charting on the Figure 9 the effect of the thickness on the power versus junction recombination velocity for $S b=S b e$.

On the curve 9, It is noticed that for a given curve, the lower values of $S f$ i.e. 


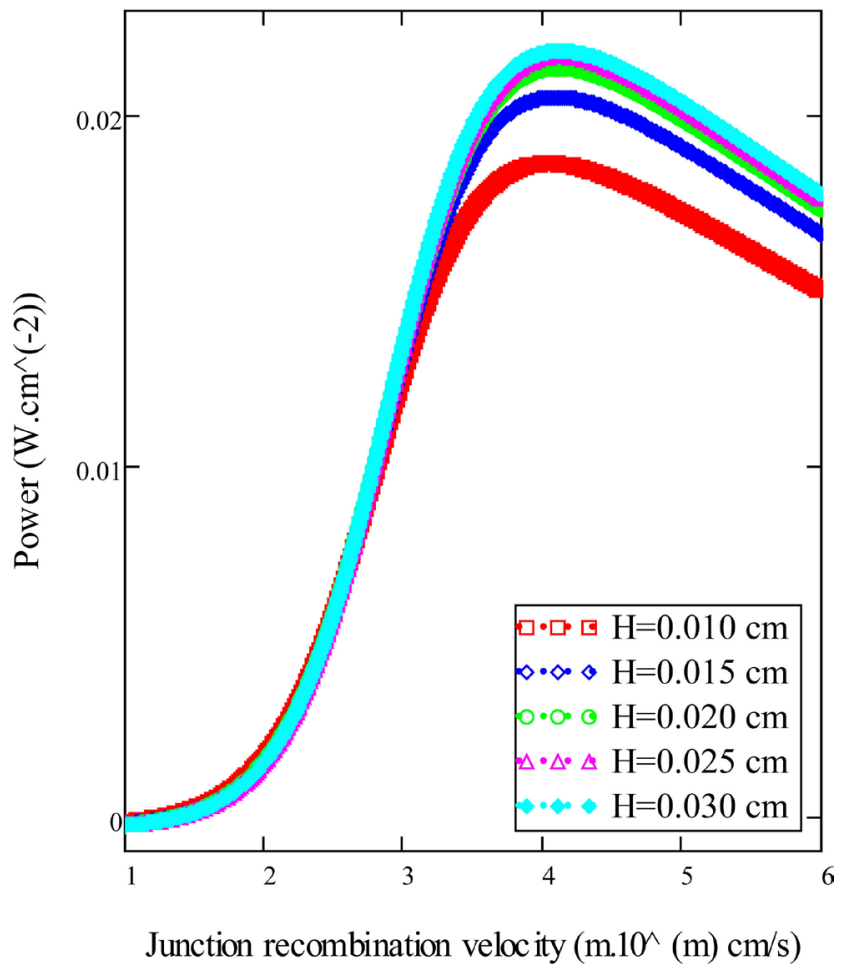

Figure 7. Power versus junction recombination velocity for different $H$ values: $S b=4 \times 10^{4} \mathrm{~cm} \cdot \mathrm{s}^{-1} ; L=0.01 \mathrm{~cm} ; H=0.03 \mathrm{~cm} ; D=26 \mathrm{~cm}^{2} / \mathrm{s}$.

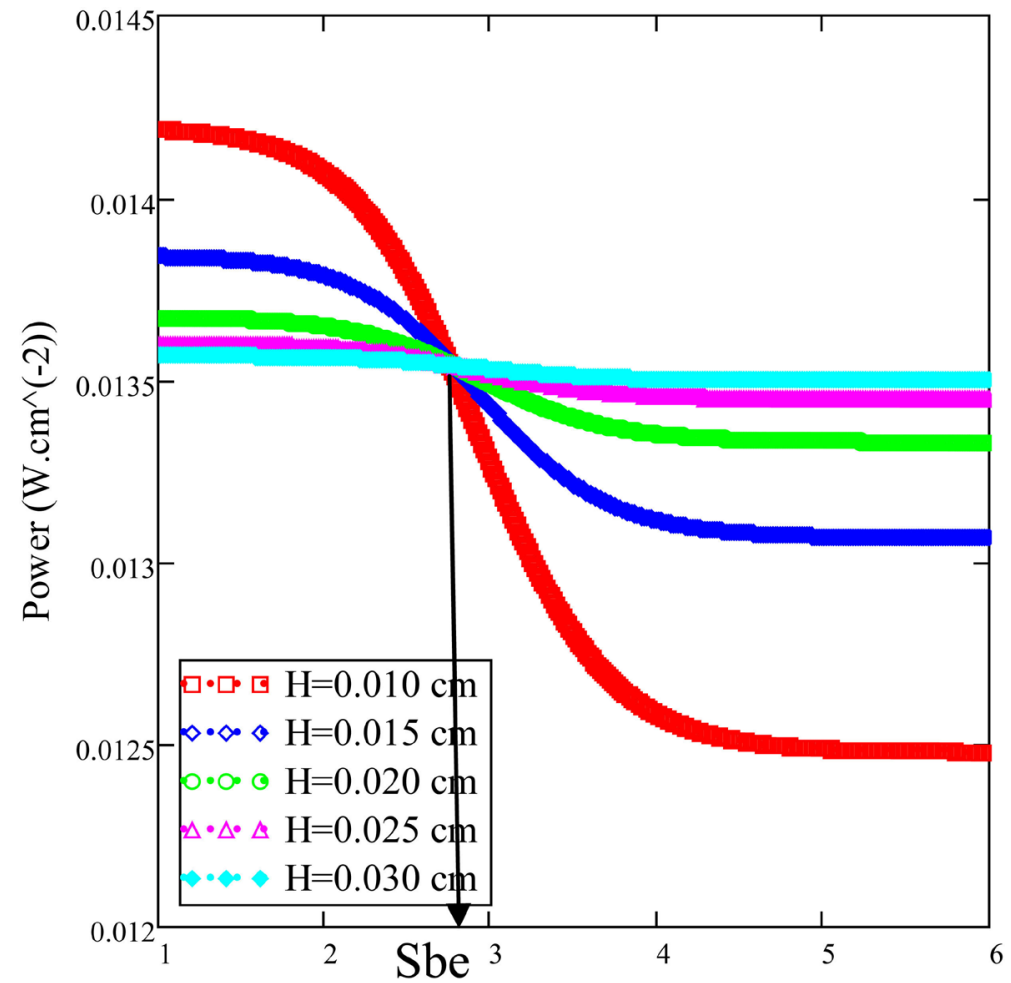

Back surface recombination velocity $\left(\mathrm{m} \cdot 10^{\wedge}(\mathrm{m}) \mathrm{cm} / \mathrm{s}\right)$

Figure 8. Power versus back surface recombination velocity for different $H$ values: $S f=3 \times 10^{3} \mathrm{~cm} / \mathrm{s}, L=0.01 \mathrm{~cm}, D=26 \mathrm{~cm}^{2} / \mathrm{s}$, Sbe $=2128 \mathrm{~cm} \cdot \mathrm{s}^{-1}$. 


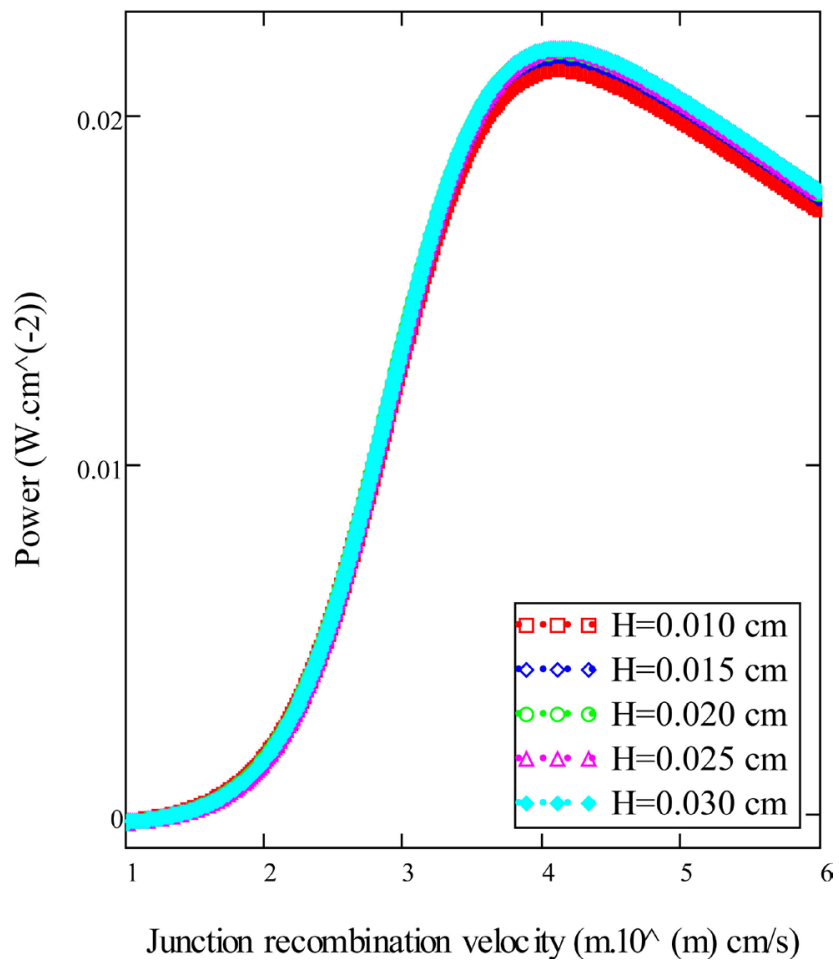

Figure 9. Power versus junction recombination velocity for different $H$ values, with $S b=$ Sbe : $S b e=2128 \mathrm{~cm} \cdot \mathrm{s}^{-1} ; L=0.01 \mathrm{~cm} ; H=0.03 \mathrm{~cm} ; D=26 \mathrm{~cm}^{2} / \mathrm{s}$.

Sf $\left.\leq 10^{2} \mathrm{~cm} \cdot \mathrm{s}^{-1}\right)$, power tends to the nil value. Because of the proximity with the open circuit, the current is low (or even nil) this therefore brings about a low power or even nil.

In the interval $10^{2} \mathrm{~cm} / \mathrm{s} \leq S f \leq 4 \times 10^{4} \mathrm{~cm} / \mathrm{s}$, the junction recombination velocity increases, the photocurrent density increases also resulting in an increase of the power to reach a maximum value corresponding to the maximum power. This maximum power therefore corresponds to a junction recombination velocity optimum that can be also obtained by the following equation

$$
\frac{\partial P}{\partial S f}=0
$$

Then for $S f \geq 4 \times 10^{4} \mathrm{~cm} / \mathrm{s}$, it tends towards the short circuit condition, then the photovoltage tends to nil value [17]. This then causes a decrease of the power which cancels itself for large $S f$ values.

Figure 8 always shows that the power decreases with the increasing back surface recombination velocity. This is from to the recombination lost factor is negligible for small $S b$ values. But when the back surface recombination velocity gradually increases, the power decreases because for $S b$ values all the carriers generated are lost via recombination.

On the contrary, Figure 7 shows that the power increases with the thickness of the solar cell. Because the photocurrent density increases with the thickness causing then an increase of the power.

In Figure 8, we notice that for a given curve, the power has a horizontal stage 
corresponding to its maximum value in the interval $S b \leq 2 \times 10^{2} \mathrm{~cm} / \mathrm{s}$.

Then, it decreases in the interval $2 \times 10^{2} \mathrm{~cm} / \mathrm{s} \leq S b \leq 4 \times 10^{4} \mathrm{~cm} / \mathrm{s}$. Finally it reaches its minimum value for $S b \geq 4 \times 10^{4} \mathrm{~m} / \mathrm{s}$. As $S b$ reflects the lost factor of recombination, when it is weak, the power reaches its most important value, then the power decreases when $S b$ increases to finally take its smallest value for the large $S b$ value. The curves show that for $S b \leq S b e$ the power decreases with the increase of the thickness. Whereas for $S b \geq S b e$, it increases with the thickness

Figure 9 shows that for $S b=S b e$, all the curves are confused. This shows that $S b e$ is a back surface recombination velocity which allows obtaining the same power whatever the solar cell thickness.

We can conclude that, for solar cells of different thicknesses, the most important power is obtained with the weakest solar cell in the case of lower back surface recombination velocity. But for high back surface recombination velocity, the most important power is obtained with the thinnest solar cell.

It is recognized that there is a back surface recombination velocity (Sbe ) which allows to obtain the same power for all thicknesses.

\subsection{Fill Factor (FF)}

It represents the fraction of the lost power in the semiconductor material either by resistance effect or by recombination phenomena of the carrier's photogenerated. It is given by the relationship:

$$
F F=\frac{P_{\max }}{V O C \cdot J S C}
$$

$P_{\max }$ is the maximum power value which can be extracted, Voc represents the open circuit photovoltage and JSC represents the short circuit photocurrent density. In Figure 10, we represent the curve of the fill factor $(F F)$ versus back surface recombination velocity for different thicknesses $H$.

Figure 10 shows that for a given curve, the fill factor $(F F)$ is constant in the interval $\mathrm{Sb} \leq 2 \times 10^{2} \mathrm{~cm} \cdot \mathrm{s}^{-1}$.

Then in the interval $2 \times 10^{2} \leq S b \leq 4 \times 10^{4}$, the fill factor decreases gradually and finally becomes constant for $S b \geq 4 \times 10^{4} \mathrm{~cm} \cdot \mathrm{s}^{-1}$. For the low values of the back surface recombination velocity that is to say in the interval $S b \leq 2 \times 10^{2} \mathrm{~cm} \cdot \mathrm{s}^{-1}$, the fill factor reaches its maximum value. Because for small $S b$ values, the loss factor of recombination is low therefore the lost power is low (Figure 8). When $S b$ rises $\left(2 \times 10^{2} \leq S b \leq 4 \times 10^{4}\right)$, the loss factor of recombination increases. The power decreases then (Figure 8 ) thus causing the decrease of the fill factor (FF). For $S b \geq 4 \times 10^{4} \mathrm{~cm} \cdot \mathrm{s}^{-1}$, the fill factor (FF) reaches its minimum value. In this interval, the lost factor reaches its maximum value leading thus to a minimum fill factor because corresponding to a minimum power (Figure 8). The curves show that the fill factor $(\mathrm{FF})$ decreases with the increase of the thickness for $S b \leq S b j$. Whereas for $S b \geq S b j$ the fill factor increases with the thickness. $S b j$ corresponds to a back surface recombination velocity which gives the same 


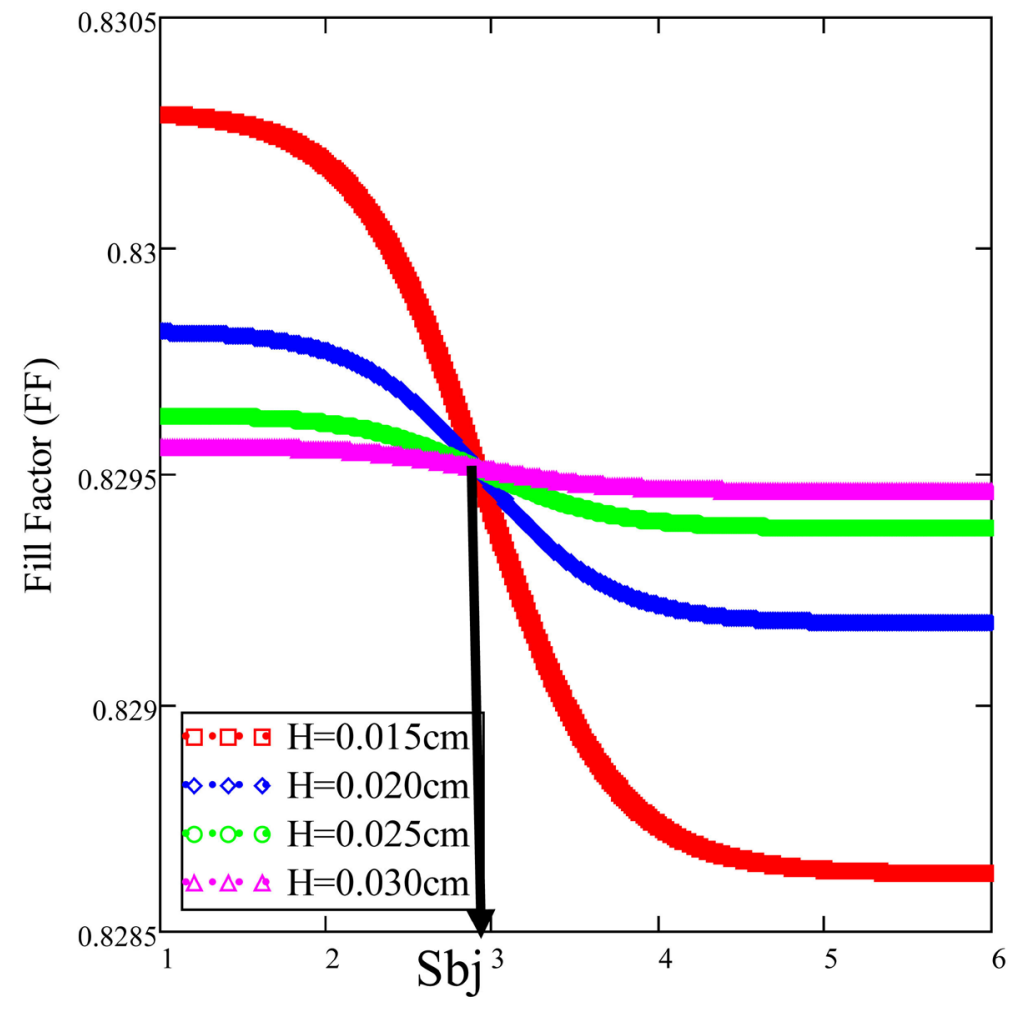

Back surface recombination velocity $\left(\mathrm{m} \cdot 10^{\wedge}(\mathrm{m}) \mathrm{cm} / \mathrm{s}\right)$

Figure 10. Fill factor versus junction recombination velocity for different $H$ values: $S f=4 \times 10^{4} \mathrm{~cm} / \mathrm{s} ; L=0.01 \mathrm{~m} ; D=26 \mathrm{~cm}^{2} / \mathrm{s}$.

fill factor regardless of the solar cell thickness.

\subsection{Conversion Efficiency}

The conversion efficiency is the fraction between electrical power generated by the solar cell and the power of the incident flux (Pinc) received by this solar cell. The maximum efficiency is, the fraction between the maximum power charged in and the forward power ( Pinc $=1 \mathrm{sun}=100 \mathrm{~mW} / \mathrm{cm}^{2}$ ). The maximum conversion efficiency is given by the following relationship:

$$
\eta=\frac{P_{m}}{\text { Pinc }} \text {, with } \text { Pinc }=100 \mathrm{~mW} / \mathrm{cm}^{2}
$$

We present in Figure 11, the profile of the conversion efficiency versus back surface recombination velocity for different thicknesses $H$.

The conversion efficiency curves versus back surface recombination velocity have the same profile.

For a given thickness $H$, the conversion efficiency is constant for $S b \leq 2 \times 10^{2} \mathrm{~cm} \cdot \mathrm{s}^{-1}$, then in the interval $2 \times 10^{2} \mathrm{~cm} \cdot \mathrm{s}^{-1} \leq S b \leq 4 \times 10^{4} \mathrm{~cm} \cdot \mathrm{s}^{-1}$, it decreases gradually and finally it becomes constant in the interval $S b \geq 4 \times 10^{4} \mathrm{~cm} \cdot \mathrm{s}^{-1}$. The curves show that for $S b \leq S b r$, the conversion efficiency decreases with the increase of the thickness, while for $S b \geq S b r$, it increases with the thickness. This allows to conclude that the thin solar cells are 


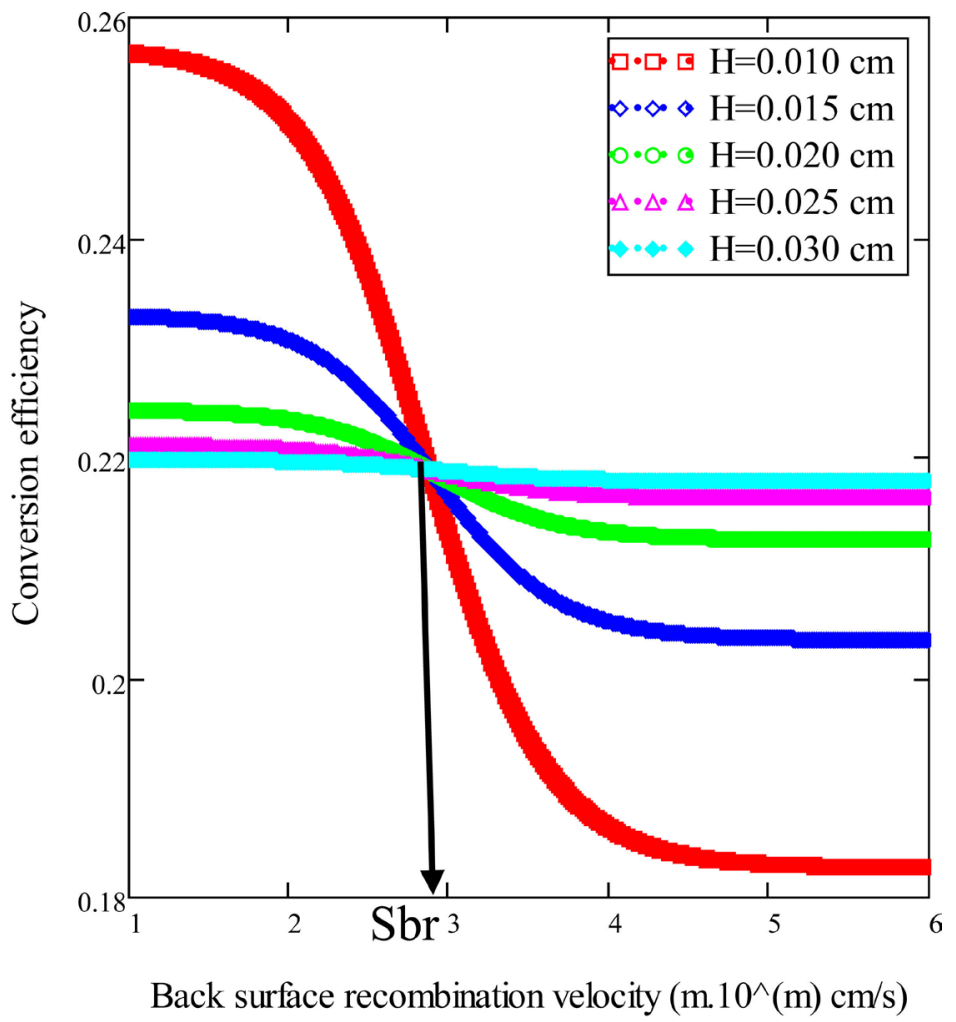

Figure 11. Conversion efficiency versus junction recombination velocity for different $H$ values: $S f=4 \times 10^{4} \mathrm{~cm} / \mathrm{s} ; L=0.01 \mathrm{~cm} ; D=26 \mathrm{~cm}^{2} / \mathrm{s}, S b r=1432 \mathrm{~cm} \cdot \mathrm{s}^{-1}$.

more advantageous than the thick one with low $S b$ values. On the other hand, in the range of high $\mathrm{Sb}$ values, thick solar cell are more advantageous. $\mathrm{Sbr}$ is a back surface recombination velocity which allows to get the same conversion efficiency with the different thicknesses of the solar cell.

\section{Conclusions}

In this work, we have studied first the profile of photocurrent density, the profile of the photo voltage and of the power. The knowledge of these parameters has allowed then to study the fill factor and the conversion efficiency.

For the photocurrent density, solar cells generate a larger photocurrent when the junction recombination velocity is high $\left(S b \geq 4 \times 10^{4} \mathrm{~cm} \cdot \mathrm{s}^{-1}\right)$. The thick solar cells $(H=0.025 \mathrm{~cm})$ are more beneficial because they generate a higher photocurrent density. For the photo voltage, the open circuit photo voltage decreases with $S b$. It also decreases with the thickness for the small $S b$ values but increases with the thickness for the high back surface recombination velocity. For the power, fill factor and conversion efficiency, we have found Sbe, Sbj and $\mathrm{Sbr}$ respectively, the back surface recombination velocities for which they are invariable whatever the solar cell thickness is.

\section{References}

[1] Ress, G.J. (1985) Solid-State Electronics, 28, 517-519. 
https://doi.org/10.1016/0038-1101(85)90116-9

[2] Ly, I., Ndiaye, M., Wade, M., Thiam, N., Gueye, S. and Sissoko, G. (2013) Research Journal of Applied Sciences, Engineering and Technology, 5, 203-208.

[3] Sharma, A.K., Agarwal, S.K. and Singh, S.N. (2007) Solar Energy Materials and Solar Cells, 91, 1515-1520. https://doi.org/10.1016/j.solmat.2007.04.018

[4] Diao, A. and Sissoko, G. (2017) Journal of Material Sciences \& Engineering, 6, 381. https://doi.org/10.4172/2169-0022.1000381

[5] Sy, K.M., Diène, A., Tamba, S., Diouf, M.S., Diatta, I., Dièye, M., Traoré, Y. and Sissoko, G. (2016) Journal of Scientific and Engineering Research, 3, 433-445.

[6] Zondervan, A., Verhoef, L.A. and Lindholm, F.A. (1988) IEEE Transactions on Electron Devices, 35, 85-88. https://doi.org/10.1109/16.2419

[7] Diallo, H.L., Wade, M., Ly, I., NDiaye, M., Dieng, B., Lemrabott, O.H., Maïga, A.S. and Sissoko, G. (2002) Research Journal of Applied Sciences, Engineering and Technology, 4, 1672-1676.

[8] Thiam, N.D., Diao, A., Ndiaye, M., Dieng, A., Thiam, A., Sarr, M., Maiga, A.S. and Sissoko, G. (2012) Research Journal of Applied Sciences, Engineering and Technol$o g y, 4,4646-4655$.

[9] Wang, C.H. (1991) IEEE Transactions on Electron Devices, 38, 2169-2180. https://doi.org/10.1109/16.83745

[10] Ndiaye, E.H., Sahin, G., Thiam, A., Dieng, M., Diallo, H.L., Ndiaye, M. and Sissoko, G. (2015) Journal of Applied Mathematics and Physics, 3, 1522-1535.

[11] Furlan, J. and Amon, S. (1985) Solid-State Electronics, 28, 1241-1243. https://doi.org/10.1016/0038-1101(85)90048-6

[12] Diallo, H.L., Maiga, A.S., Wereme, A. and Sissoko, G. (2008) The European Physical Journal Applied Physics, 42, 203-211. https://doi.org/10.1051/epjap:2008085

[13] Sissoko, G., Museruka, C., Corréa, A., Gaye, I. and Ndiaye, A.L. (1996) Light Spectral Effect on Recombination Parameters of Silicon Solar Cell. World Renewable Energy Congress 3, Denver, 1487-1490.

[14] Joardar, K., Dondero, R.C. and Schroda, D.K. (1989) Solid-State Electronics, 32, 479-483. https://doi.org/10.1016/0038-1101(89)90030-0

[15] Sissoko, G., Nanéma, E., Ndiaye, A.L., Bocandé, Y.L.B. and Adj, M. (1996) Renewable Energy, 3, 1594-1597.

[16] Bocande, Y.L.B., Correa, A., Gaye, I., Sow, M.L. and Sissoko, G. (1994) Renewable Energy, 5, part III, 1698-1700.

[17] Sissoko, G., Nanéma, E., Corréa, A., Biteye, P.M., Adj, M. and Ndiaye, A.L. (1998) Renewable Energy, 3, 1848-1851. 